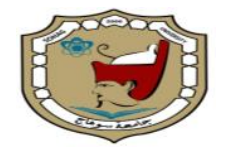

Sohag University
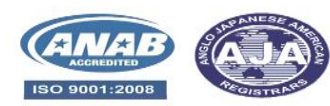

Sohag Medical Journal

\title{
Early Detection of Subclinical Nephritis in Systemic Lupus Erythematosus Patients
}

\author{
Rana N. Saad-eldin ${ }^{1}$, Esam M. Abu Al-Fadl 1, Nehal A. Fathi ${ }^{2}$, Afaf T. \\ Ibrahi $^{3}$
}

1 Department of Physical Medicine, Rheumatology \& Rehabilitation, Sohag University

2 Department of Physical Medicine, Rheumatology \& Rehabilitation, faculty of medicine, Assuit University

3 Department of Pathology, faculty of medicine, Sohag University

\begin{abstract}
Systemic lupus erythematosus (SLE) is an autoimmune disorder affecting many systems in the body. Because of the disease's tremendous variety, some researchers believe that it is a syndrome rather than a single disease. One of the most prevalent manifestations of SLE is lupus nephritis (LN). Nearly $40 \%$ to $70 \%$ of patients with SLE have LN.

The manifestations of $\mathrm{LN}$ range from asymptomatic urinary findings to nephrotic syndrome and progressive renal impairment. The International Society of Nephrology and the Renal Pathology Society (ISN/ RPS) have indicated that the various LN classes exhibit different natural history and clinical patterns. Subclinical lupus nephritis (SLN) is nephritis diagnosed via renal biopsy despite normal urinalysis. Renal biopsy is the most important procedure to detect renal damage and SLN.

Keywords: Lupus nephritis, Subclinical nephritis, Systemic lupus erythematosus.
\end{abstract}

\section{Introduction}

SLE is an autoimmune disorder affecting many systems in the body. Because of the disease's tremendous variety, some researchers believe that it is a syndrome rather than a single disease. One of the most prevalent manifestations of SLE is lupus nephritis (LN) with $40 \%$ $70 \%$ of patients having it. During a flare-up of SLE, inflammatory injury to the nephrons is known aslupus nephritis. ${ }^{(1-3)}$ Not only can varied clinical images be seen in the same patient, but also may be changing from normal to severe damage to the kidney. Patients having $\mathrm{LN}$ differ in clinical manifestations and duration of illness. Severe damage of the kidney occurs quickly through intense inflammation. It may be reversible with the right medications that suppress the immunity, however, end stages of $\mathrm{LN}$ do not respond to these medications. ${ }^{(4)}$ Subclinical lupus nephritis (SLN) is diagnosed when renal biopsy reveals pathological evidence of nephritis in patients having no or little proteinuria and normal laboratory markers. ${ }^{(5)}$ As a result, it's assumed that the true prevalence of $\mathrm{LN}$ is larger thanwhat's been reported; about 60\%-70 $\%$ of cases are Class I / II LN - suggesting mild nephritis, while 15\%-20\% of cases are a class III / IV LN — with bad prognosis. ${ }^{(6}$ and 7$)$ The most approved pr-ocedure to detect nephritis in SLE pat-ients is renal biopsy. However, no obvi-ous criteria for renal biopsy have yet been established.

$\beta 2$ microglobulin (B2M) is generally 
detected in serum, urine, and other bodily fluids, and is virtually entirely broken down within the kidney; glomerular filtration eliminates 95 percent to 100 percent of circulating $\beta 2 \mathrm{M}$. The cause that the $\beta 2 \mathrm{M}$ level is high in $\mathrm{LN}$ is vague, it may be due to the higher lymphocyte transformation seen in SLE patients. ${ }^{(8)}$

\section{Epidemiology}

Lupus prevalence rates in the United States range from 100 per 100,000 white women to 400 per 100,000 black women. Two and 8 per 100,000 per year is the estimated rate in North America, South America, and Europe. ${ }^{(9)}$

\section{Etiology}

SLE female patients having both hereditary and environmental factors which influence the pathogenesis. Immunological toleranceis irreversibly broken and endogenous nuclear antigen causes immune responses to them.

\section{Pathogenesis}

In SLE, increased autoantigen production during apoptosis (UV induced or spontaneous), reduced disposal, and presentation are all involved in the autoimmune response beginning.

Apoptotic blebs include nucleosomes that contain endogenous danger ligands that can bind to pathogen-associated $\mathrm{m}$ olecular pattern receptors, promoting DC, ${ }^{(10)}$ IFN alpha, and autoantibodies produced by $\mathrm{B}$ cell activation.

\section{Classification criteria}

In 1971, criteria for SLE were established and in 1982 it was reviewed and in 1997 reviewed again. the most recent one is the 2019 EULAR/ACR classification criteria (Table-1).

\section{SLE Disease Activity Index (S- LEDAI)}

The change in disease activity and the predictors of damage and mortality had been observed by studies and consequently, the SLEDAI score has been developed. ${ }^{(12)}$

Subclinical lupus nephritis (SLN) includes patients in whom renal biopsy was abnormal in presence of little or no proteinuria and normal lab markers. ${ }^{(5)}$

\section{Lupus nephritis (LN)}

is one of the most prevalent and debilitating manifestations of (SLE), affecting more than $40 \%-60 \%$ of SLE patients. During SLE flare, inflammatory damage to the nephrons causes lupus nephritis. Not only unique Clinical images, as well as varying from normal kidney, to damage kidney. ${ }^{(13)}$

\section{Criteria for diagnosing lupus nephritis}

Proteinuria more than $0.5 \mathrm{~g} / \mathrm{day}$, or more than $3+$ urinary dipstick protein, $\mathrm{P} / \mathrm{C}$ ratio $>0.5 \mathrm{mg} / \mathrm{mg}$ or more than five cells per high-power field of urinary cellular casts without infection of the urinary systemare all considered LN by criteria of the ACR lupus classification criteria. ${ }^{(14)}$ The World Health Organization (WHO) classified LN in 1974 based onlyon glomerular lesions, and it went through several revisions until the Inte-rnational Society of Nephrology (ISN) and the Renal Pathology Society (RPS) came up with the most widely accepted classification (Table-2). 
Table-1. 2019 EULAR/ACR classification criteria for systemic lupus erythematosus (SLE) (11)

\begin{tabular}{|c|}
\hline Entry criterion \\
Antinuclear antibodies (ANA) at a titer of $\geq 1: 80$ other-2cells or an equivalent positive test (ever) \\
$\downarrow$ \\
\hline If absent, do not classify as SLE \\
If present, apply additive criteria \\
\hline
\end{tabular}

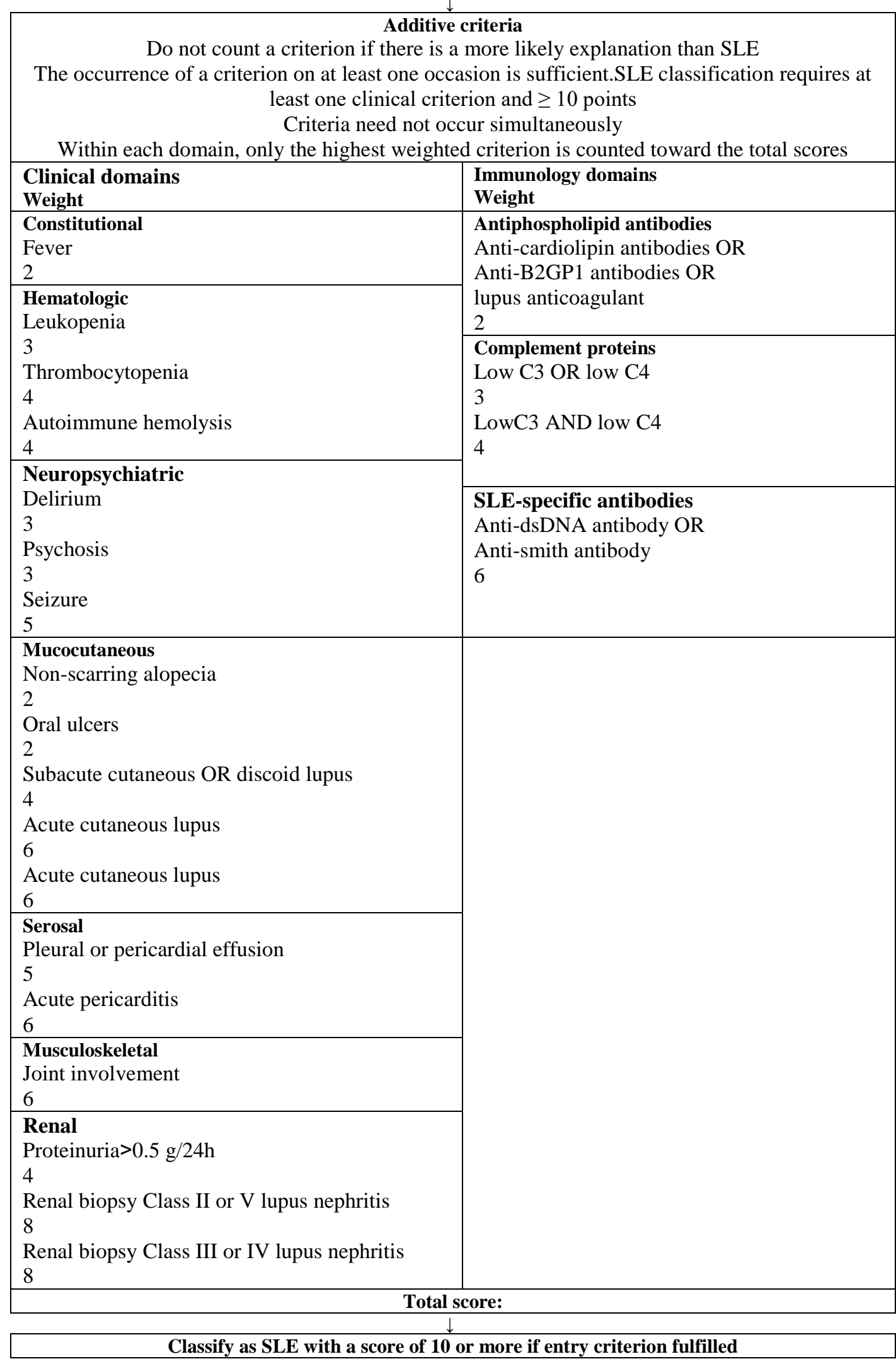


Table-2: Classification of lupus nephritis (15).

\begin{tabular}{|l|l|}
\hline ISN/RPS class & Description \\
\hline I & Minimal Mesangial Lupus Nephritis \\
\hline II & Mesangial proliferative Lupus Nephritis \\
\hline III & Focal Lupus Nephritis \\
\hline IV & Diffuse Lupus Nephritis \\
\hline V & Membranous Lupus Nephritis \\
\hline VI & Advanced Sclerosing Lupus Nephritis \\
\hline
\end{tabular}

\section{Pathogenesis}

Multiple variables, including genetic, epigenetic, and environmentalvariables are involved in the pathogenesis of SLE and LN. It's marked by a loss ofself- tolerance that leads to polyclonal antibody activation, which shows up in the form of a positive ANA and a full-house pattern on immunofluorescence in renal biopsy specimens.

T-cells and activators of B-cells are activated by the innate immune system in the early stages of illness, which leads to adaptive immune responseactivation of $\mathrm{T}$ - cells, such as type $1 \mathrm{~T}$-helper (TH1) cells and TH17, are responsible forB-cell activation both systemically and intrarenal. After being activated by $T$ cells or the innate immune system, B cells produce a variety of autoantibodies and cytokines. ${ }^{(16)}$

\section{Renal Biopsy}

The most important procedure to detect renal disease is a renal biopsy that was first time used in $1951 .^{(17)}$

\section{Role of renal biopsy in ( $\mathrm{LN})$}

$\mathrm{LN}$ is a histological diagnosis despite the existence of clinicalcriteria. The LN diagnosis is unmistakable thanks to the kidney biopsy. It gives proof for disease prediction, activity, chronicity, andtherapeutic planning. Because LN therapy includes potentially harsh medicines, starting treatment without a clear diagnosis could be dangerous. Extraglomerular symptoms of SLE, such as TMA, non-lupus renal illness, or drug-induced interstitial nephritis, may be present in SLE patients who have signs suggestive of renal involvement, all of which have different therapy and results. As a result, kidney biopsy is considered a must-have in the treatment of LN. Proteinuria $>0.5 \mathrm{~g} / \mathrm{day}, 5 \mathrm{red}$ blood cells or white blood cells detected by high-power field, typically dysmorphic withoutsigns of infection or rising seru$\mathrm{m}$ creatinine are the most common reasons for a first kidney biopsy. ${ }^{(18)}$

\section{Beta-2 Microglobulin (B2M)}

In 1964, B2M was detected in the urine of peoplesuffering from Wilson's disease or cadmium poisoning. The structure of B2M consists of 100 amino acids with a low molecular weight $(11,800$ Da, size 11) that's encoded by a human gene on chromosome $15 .{ }^{(19)}$

\section{Using B2M to Assess Glome-rular Function}

Renal function can be measured in a variety of methods, the most common method used is glomerular filtration rate. This is accomplished by determining filtration marker clearance in plasma or in urine. B2M is a perfect en-dogenous marker that appears at a constant rate in plasma, the glomeruli filter B2M freely, not removed from extrarenal sites, tubules do not secrete $\mathrm{B} 2 \mathrm{M}$ and are not absorbed into the circulation. ${ }^{(20)}$

\section{Urinary markers can be predictors of renal damage}

such as $\operatorname{IgG}(150 \mathrm{kD})$ which is a protein of high molecular weight excreted in large quantities when permselectivity of the glomerular capillary wall is severely disrupted. ${ }^{(21)}$ 
Therefore, these proteins could be markers of the severity of glomerular damage.

Monocyte chemoattractant protein-1 (MCP-1) is a leukocyte chemotactic factor that is involved in mediating inflammation and injury in lupus nephritis (22).

In lupus nephritis, increased expression of MCP-1 on endothelial cells, renal epithelial cells, and infiltrating mononuclear cells in the tubulointerstitial regions can be demonstrated by immunohistochemical staining. ${ }^{(23)}$

Urinary Tumor necrosis factor receptor (TNFR) is part of the superfamily of TNF receptors which regulate the signaling of survival, proliferati6on, differentiation, and action of the immune and non-immune system cells ${ }^{(24) \text {. TNFR }}-1$ is expressed in the glomerulus and di-stal and collecting tubules. High urina-ry levels correlate significantly in patients with active LN. ${ }^{(25)}$

Urinary Interleukin-6 (IL-6) is a pleiotropic cytokine produced by monocytes, $\mathrm{T}$ and $\mathrm{B}$ lymphocytes, fibroblasts, endothelial cells, and mesangial cells. ${ }^{(26)}$ The IL-6 production in mesangial cells, tubule epithelial cells, endothelial cells, and podocytes, have linked this cytokine to $\mathrm{CKD}$, acute kidney disease (AKD) and LN. (27)

N-acetyl-b-D-glucosaminidase (NAG) is a hydrolase-class enzyme, found abundantly in the lysosomes of cells located in the proximal tubules (28). Elevated urinary levels of NAG have been found in patients with $\mathrm{LN}$ compared with healthy individuals. Additionally, high levels of this enzyme correlate with proteinuria. ${ }^{(29)}$

Urinary epidermal growth factor: Hefny et al raised the attention to test the sensitivity of urinary EGF in detecting the early and the subsequent changes in renal pathology of SLE patients as an easy, non-invasive, accurate, cheap marker that could help in following up the nephritis progression and adjusting the plan of treatment; also, it can be used to guide the time of biopsy or as an alternative in cases when the renal biopsy is contraindicated. ${ }^{(30)}$

\section{References}

1. Sutton EJ, Davidson JE, Bruce IN. The systemic lupus international collaborating clinics (SLICC) damage index: a systematic literature review. Semin Arthritis Rheum. 2013;43:352361.

2. Lopez R, Davidson JE, Beeby MD, et al. Lupus disease activity and the risk of subsequent organ damage and mortality in a large lupus cohort. Rheumatology (Oxford) 2012;51:491-498.

3. Danila MI, Pons-Estel GJ, Zhang J, et al. Renal damage is the most important predictor of mortality within the damage index: data from LUMINA LXIV, a multiethnic cohort. Rheumatology (Oxford) 2009;48:542545.

4. Davidson A, Aranow C. Lupus nephritis: lessons from murine models. Nat Rev Rheumatol. 2010;6:13-20.

5. Ding J, Zheng Z, Li X, et al. Urinary Albumin Levels are Independently Associated with Renal Lesion Severity in Patients with Lupus Nephritis and Little or No Proteinuria. Med Sci Monit. 2017;23:631-639.

6. Zabaleta-Lanz ME, Muñoz LE, Tapanes FJ, et al. Further description of early clinically silent lupus

nephritis, Lupus, 2006, vol. 15 (pg. 84 5-51)

7-. Wakasugi D, Gono T, Kawaguchi Y, et al. Frequency of class III and IV nephritis in systemic lupus erythematosus without clinical renal involvement: an analysis of predictive measures, $\mathrm{J}$

Rheumatol, 2012, vol. 39 (pg. 798515.

8- Żychowska Iwona. $\beta 2$-microglobulin as a marker of systemic lupus erythematosus activity. Advances in Clinical and Experimental Medicine. Adv Clin Exp Med. 2018; 27(3): 37982. 
9- Danchenko N, Satia JA, Anthony MS (2006). "Epidemiology of systemic lupus erythematosus: a comparison of worldwide disease burden". Lupus. 15 (5): $308-18$

10-- Rönnblom L, Pascual V. The innate immune system in SLE: type I interferons and dendritic cells. Lupus. 2008;17:394-9.

11- Aringer, M; Costenbader, K; Daikh, D; Brinks, R; Mosca, M; RamseyGoldman, R; et al. "2019 European League Against Rheumatism/American College of Rheumatology Classification Criteria for Systemic Lupus Erythematosus". Arthritis \& Rheumatology. 71 (9): 1400-1412.

12-- Gladman, D. D., Ibanez, D. \& Urowitz, M. B. Systemic lupus erythematosus disease activity index 2000. J. Rheumatol. 29, 288-291 (2002.

13--: US patients of Hispanic and African ancestry develop lupus nephritis early in the disease course: Data from LUMINA, a multiethnic US cohort (LUMINA LXXIV). Ann Rheum Dis 70: 393-394, 2011.

14- Hochberg MC. Updating the American College of Rheumatology revised criteria for the classification of systemic lupus erythematosus. Arthritis Rheum. 1997;40:1725.

15- Weening JJ, D'Agati VD, Schwartz MM, Seshan SV, Alpers CE, Appel $\mathrm{GB}$, et al. The classification of glomerulonephritis in systemic lupus erythematosus revisited. J Am Soc Nephrol. 2004;15:241-50.

16- Lech M, Anders HJ. The pathogenesis of lupus nephritis. J Am Soc Nephrol. 2013;24:1357-66

17- Fogo, A.B. Approach to renal biopsy. Am J Kidney Dis. 2003; 42: 826-836.

18- Hahn BH, McMahon MA, Wilkinson A, Wallace WD, Daikh DI, Fitzgerald $\mathrm{JD}$, et al. American College of Rheumatology guidelines for screening, treatment, and management of lupus nephritis. Arthritis Care Res (Hoboken) 2012;64:797-808

19-- Iwata K, Matsuura T, Sakurai K, Nakagawa A, Goto Y. High-resolution crystal structure of beta2-microglobulin formed at $\mathrm{pH}$ 7.0. J

Biochem (2007) 142:413-9.10.1093.

20- Inker LA, Tighiouart H, Coresh J, Foster MC, Anderson AH, Beck GJ, et al. GFR estimation using $\beta$-trace protein and $\beta 2$-microglobulin in CKD. Am J Kidney Dis (2016) 67:408 ?

21-Tofik R, Aziz R, Reda A, et al: The value of IgG-uria in predicting renal failure in idiopathic glomerular diseases. A long-term follow-up study. Scand J Clin Lab Invest, 2011; 71: 12328.

22- Rovin BH, Birmingham DJ, Nagaraja $\mathrm{HN}$, Yu CY, Hebert LA. Biomarker discovery in human SLE nephritis. Bulletin of the NYU Hospital for Joint Diseases. 2007;65(3):187193)

23-Wada T, Segawa C, Su SB, et al. Monitoring urinary levels of monocyte chemotactic and activating factor reflects disease activity of lupus nephritis. Kidney International. 1996;49(3):761-767)

24-Dostert C., Grusdat M., Letellier E. The TNF family of ligands and receptors: system and beyond. Physiol. Rev. 2018;99:115-160.)

25- Wu T., Xie C., Wang H.W. Murine lupus strains and human lupus nephritis 1. J. Immunol. 2007;179:7166-7175).

26-. Kishimoto T., Akira S., Narazaki M. Interleukin-6 family of cytokines and gp130. J Am Soc Hematol. 2018;86:1243-1254

27-[Su H., Lei C., Zhang C. Interleukin-6 signaling pathway and its role in kidney disease: an update. Front. Immunol. 2017;8:1-10.)

28-Genctoy G., Arikan S. Urinary NAcetyl-Beta-D glucosaminidase activity is associated with inflammation and proteinuria in diabetic and nondiabetic patients with different stages of chronic kidney disease. Turkish J Nephrol. 2015;24:166-173.

29- Gluhovschi C., Velciov S., Kaycsa A. The dynamics of urinary $\mathrm{N}$-acetyl- $\beta$ d-glucosaminidase ( NAG ), a marker of renal tubular dysfunction, in patients with lupus nephritis undergoing oral prednisone therapy. 
Immunopharmacol. Immunotoxicol. 2012;34:163-169.

30- Hefny, H. M., Abualfadl, E. M., Youssef, E. A., Ismail, M. A., Soliman, T. M., Ahmed, A. R. H., \& Abozaid, H. S. (2021). Urinary epidermal growth factor as a marker for lupus nephritis: clinical, laboratory, and histopathological study. Egyptian Rheumatology and Rehabilitation, 48-1 ،(1)8 . 